\title{
Endosperm: an integrator of seed growth and development Frédéric Berger ${ }^{1}$, Paul E Grini ${ }^{2}$ and Arp Schnittger ${ }^{3}$
}

Plant reproduction relies on interactions between parental and zygotic components. Elaborate reciprocal signaling pathways enable coordination of the genetic programs between these components. A first and important step in this communication is the tight control of cell cycle events in the gametes prior to fertilization. This prepares for coordinated fertilization and the initiation of seed development. The dialog between the various actors of reproduction extends after fertilization, with the endosperm taking a central role. Importantly, the endosperm mediates a maternal input that is based on memory of the transcriptional states of imprinted genes, which is crucial for harmonious seed growth. Our current knowledge suggests that the endosperm is an integrator of the different components and genetic programs that are involved in seed development.

\author{
Addresses \\ ${ }^{1}$ Temasek Lifescience Laboratory, 1 Research Link, National University \\ of Singapore, 117604, Singapore \\ ${ }^{2}$ Department of Molecular Biosciences, University of Oslo, Blindernveien \\ 31, 0316 Oslo, Norway \\ ${ }^{3}$ University group at the Max-Planck-Institute for Plant Breeding \\ Research, University of Cologne, Department of Botany III, Max- \\ Delbrück-Laboratorium, Carl von Linné Weg 10, 50829 Köln, Germany
}

Corresponding author: Berger, Frédéric (fred@tll.org.sg), Grini, Paul E (p.e.grini@bio.uio.no) and Schnittger, Arp (schnitt@mpiz-koeln.mpg.de)

\section{Current Opinion in Plant Biology 2006, 9:664-670}

This review comes from a themed issue on

Cell biology

Edited by Laurie G Smith and Ulrike Mayer

Available online 29th September 2006

1369-5266/\$ - see front matter

(C) 2006 Elsevier Ltd. All rights reserved.

DOI 10.1016/j.pbi.2006.09.015

\section{Introduction}

In plants, the diploid generation produces a special lineage leading to meiosis. The haploid meiotic products (spores) then develop as morphologically distinct life forms, the male and female gametophytes, which will differentiate a germ-line and produce the male and female gametes (Figure 1). In flowering plants, double-fertilization has evolved parallel to specialization of the haploid gametophyte towards reproduction. The gametophytic life form has been drastically reduced to be nearly equivalent to the germ line. In Arabidopsis, as in the majority of flowering plants, the pollen grain develops from an initial asymmetric division of the haploid meiotic product, Pollen Mitosis I (PMI) (Figure 1). The smaller generative cell undergoes PMII and divides again, giving rise to two sperm cells. The female embryo sac develops from only one of the meiotic products and typically undergoes three successive syncytial divisions followed by cellularization into seven cells, including the two female gametes, namely the egg cell and the central cell (Figure 1; [1]).

At the time of fertilization, the pollen grain grows a pollen tube that delivers the two sperm cells to the embryo sac. Despite significant advances in our understanding of guidance mechanisms for the pollen tube and the transcriptional activity of the gametes [2-4], our knowledge on the actual mechanism of fertilization remains extremely limited. A remarkable recent study has shown, however, that the fusion between the sperm cells and the female gametes involves the conserved protein GENERATIVE CELL SPECIFIC 1 (GCS1) [5 ${ }^{\bullet \bullet}$ ]. One sperm cell fertilizes the egg cell, giving rise to a zygote from which the embryo develops. The other sperm cell fuses with the central cell generating the endosperm, which nurtures embryo development in the seed (Figure 1).

In this review, the signaling events that follow doublefertilization in flowering plants are outlined with particular emphasis on the following points. What signals control the cell cycle at fertilization? What mechanisms co-ordinate the relative growth of the three main seed components, the embryo, the endosperm and the maternal seed integuments? Finally, what roles do gametes play in embryo and endosperm development?

\section{Control of cell cycle progression before and after fertilization}

In contrast to cell cycle control in animal gametes, cell cycle control in plant gametes has remained largely unknown until recently. In Arabidopsis, direct measurements of DNA content suggest that sperm cells enter a new $\mathrm{S}$-phase after PMII, which is presumably completed either before or during pollen tube growth [6,7]. Thus, when delivered to the embryo sac, sperm cells are likely to be in $G_{2}$ phase [8]. Further evidence of a fusion at $G_{2}$ phase comes from a mutant in the Arabidopsis cyclindependent kinase gene $C D K A ; 1$, which encodes a homo$\log$ of the yeast cdc2a kinase. In $c d k a ; 1$ mutant pollen, the generative cell fails to enter PMII and remains in the $\mathrm{G}_{2}$ phase with a DNA content of about $2 \mathrm{C}\left[9^{\bullet \bullet}, 10\right]$. Importantly, this mutant pollen is able to complete fertilization $\left[9^{\bullet \bullet}\right.$. To prevent aneuploidy and allow proper development of the zygote, the two nuclei of the gametes need to fuse in the same cell cycle phase. The simplest assumption derived from the cell cycle phase of the male gamete is that female gametes also reach the $G_{2}$ phase, matching 


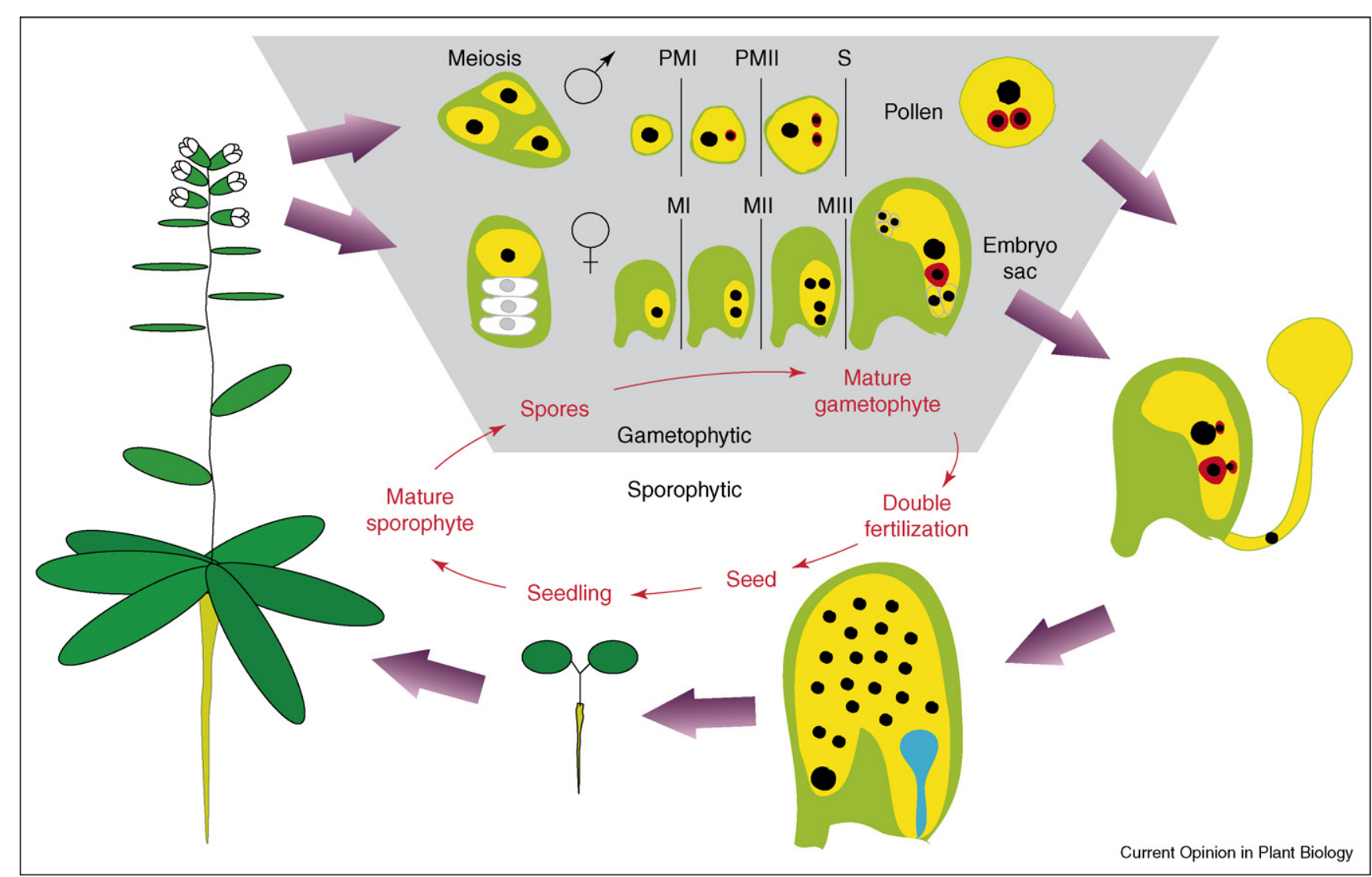

Life cycle of flowering plants. In flowering plants, the predominant life form is the sporophyte (the green plant). In the flowers, the sporophyte will asexually generate female and male spores. The male spore will undergo two rounds of cell divisions, PMI and PMII. The mature pollen comprises a large vegetative cell and embedded in this, two sperm cells, the actual gametes (shown with red cytoplasm). Female gametogenesis includes three rounds of nuclear divisions followed by cellularization, resulting in a seven-cell embryo sac. The embryo sac contains the egg cell (again shown with red cytoplasm) flanked by two synergid cells and the central cell (shown in yellow), which contains a large nucleus. During the double fertilization process, sperm cells are delivered by the pollen tube to the embryo sac. One sperm cell fuses with the egg cell and generates the zygote, whereas the second sperm cell fuses with the central cell, giving rise to the endosperm. The endosperm supports the developing embryo. Double-fertilization represents the end of the gametophytic life stage and the beginning of the sporophytic phase.

the cell cycle stage of sperm cells. This assumption was recently supported by measurements of DNA content in tobacco gametes [8].

Conserved chromatin remodeling Polycomb group (Pc-G) complexes control the arrest of the Arabidopsis female gametophyte. The Pc-G complex FERTILIZATION INDEPENDENT SEED (FIS) contains the SET domain protein MEDEA (MEA) [11], the VEFS domain protein FIS2 [12], and the WD40 domain protein FERTILIZATION INDEPENDENT ENDOSPERM (FIE) [13]. Loss-of-function mutations of FIS genes cause autonomous onset of cell division in the central cell in the absence of fertilization $[14,15]$. The FIS complex also includes the WD40 protein MULTICOPY SUPPRESSOR OF IRA 1 (MSI1) [16,17]. Unexpectedly, when compared to the fis mutants, $m s i$ mutants show additional autonomous division in the egg cell that leads to a non-viable parthenogenetic embryo [18 ${ }^{\bullet}$. This suggests that partially distinct mechanisms control the arrest of the egg cell and the central cell (Figure 2a).

MSI1 interacts with plant homologs of the mammalian tumor suppressor protein Retinoblastoma (Rb) [19]. Autonomous cell proliferation in the embryo sac has been reported in plants that carry null alleles of the Arabidopsis Rb homolog RBR1 [20]. However, the pleiotropy of the phenotype has prevented unambiguous identification of the origin of proliferating cells in $r b r 1$. The $r b r 1$ mutant phenotype is likely to be compound. RBR1 can interact with components of the FIS-complex [21], but could also act upstream of the FIS Pc-G complex and together with MSI1 to directly control cell cycle progression in the female gametophyte. In analogy to its function in root stem cells, RBR1 might also be involved in specifying gamete identity [22]. 


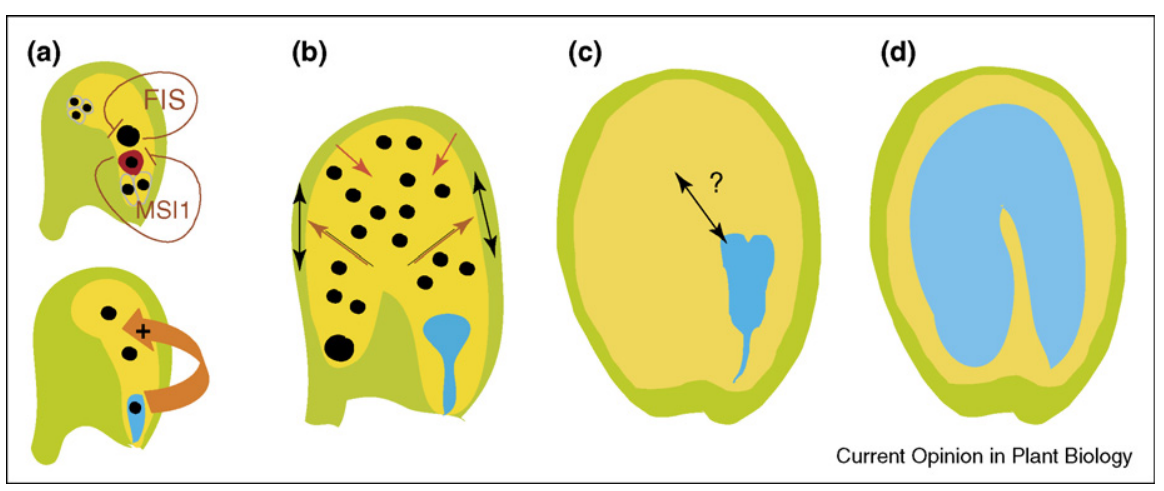

Interactions between seed components. (a) Before fertilization, a negative signal embodied by the action of the chromatin remodeling complex FIS restricts the premature proliferation of the central cell. An equivalent repression depends on MSI1 and targets the egg cell. After fertilization, a positive signal is derived from the fertilization of the egg cell that triggers endosperm development if the central cell is not fertilized. The origin and nature of this positive signal is currently not known. (b) During later stages, reciprocal signaling between the endosperm (yellow with black nuclei), the embryo (blue) and the seed integuments (green) is required to achieve proper seed growth. The endosperm takes a central role as an integrator and mediator of these signals. The endosperm controls cell elongation (black double arrows) in the seed integuments (dark red arrows). Reciprocally, the seed integuments restrict the potential growth of the endosperm (red arrows). As a result, the final seed size is determined. (c) Finally, endosperm trophic inputs and potential signals to the embryo sustain cell proliferation in the embryo. (d) At the mature stage, the embryo occupies most of the space initially created by the interactions between the endosperm and the seed integuments.

In conclusion, the cell cycle arrest of the central cell is controlled by the FIS pathway, whereas the egg cell arrest probably depends on a MSI1-dependent action that is independent of the Polycomb Group FIS pathway. Proper differentiation of both female gametes might involve the function of RBR1. A recent report [ $9^{\bullet \bullet}$ ] on a functional knock-out of the Arabidopsis CDKA1;1 has provided evidence for mechanisms that might be involved in cell-cycle control prior to fertilization.

\section{Co-ordination of growth between the different seed components}

During seed growth, co-ordination is necessary between the embryo, the endosperm, the maternally contributed seed integuments and the nucellus, which is also of maternal origin. No experimental data have yet been obtained for the role of the nucellus, but recent advances have demonstrated that interplay between endosperm and seed integument growth is essential for seed size determination in Arabidopsis (Figure 2). Mutations in the $H A I K U(I K U)$ genes decrease endosperm size and eventually embryo and seed size [23]. The HAIKU genes IKU2 and MINISEED3 (MINI3) encode a leucine-rich-repeat kinase and a WRKY transcription factor, respectively [24]. These genes are expressed in endosperm immediately after fertilization. The decreased endosperm size of $i k u$ mutants is accompanied by a decrease in cell elongation in the seed integuments, indicating communication between these two genetically distinct seed components (Figure 3c-f; [25 ]). Similarly, reducing the degree of cell elongation in the seed integuments reduces endosperm growth. Conversely, increasing the number of seed integument cells causes a symmetrical increase in endosperm growth [26,27]. In Arabidopsis, the final size of the seed is determined before the embryo initiates the major phase of cell proliferation after the heart embryo stage (Figure 2). These results indicate the capacity of seed integuments to regulate endosperm growth by a maternal sporophytic effect (Figure 2b). In cereal species, the embryo remains confined to a small volume in the mature seed and the endosperm extends its development until seed maturity and stores reserves. Hence, the model of seed size control established in Arabidopsis is likely to be applicable to seed development in cereals. The mechanistic nature of the communication between the endosperm and the integuments remains unknown. A likely factor could be biophysical forces; a growing endosperm might exert mechanical tensions on the integument cells $\left[25^{\circ}, 28\right]$.

How the embryo adjusts its degree of cell proliferation to the space available (as seen in $i k u$ seeds) is not yet understood. However, this observation indicates some kind of communication from the endosperm to the embryo. Communication from the embryo to the endosperm has been revealed by analysis of the mutant for the Arabidopsis homolog of the cyclin dependent kinase $c d c 2 a$, CDKA;1 [9 $9^{\bullet \bullet}$. In heterozygous $c d k a ; 1$ null mutants, $50 \%$ of the pollen contain a single sperm cell $\left[9^{\bullet \bullet}, 10\right]$ that exclusively fertilizes the egg cell. The development of the zygotic embryo has a dramatic effect because it triggers nuclear divisions of the central cell and initiates endosperm development (Figures 3a,b; [9 $\left.9^{\bullet \bullet}\right]$ ). Thus, either the fertilization process or the developing embryo provides a signal that counteracts cell cycle arrest in the central cell and stimulates endosperm development 
Figure 3

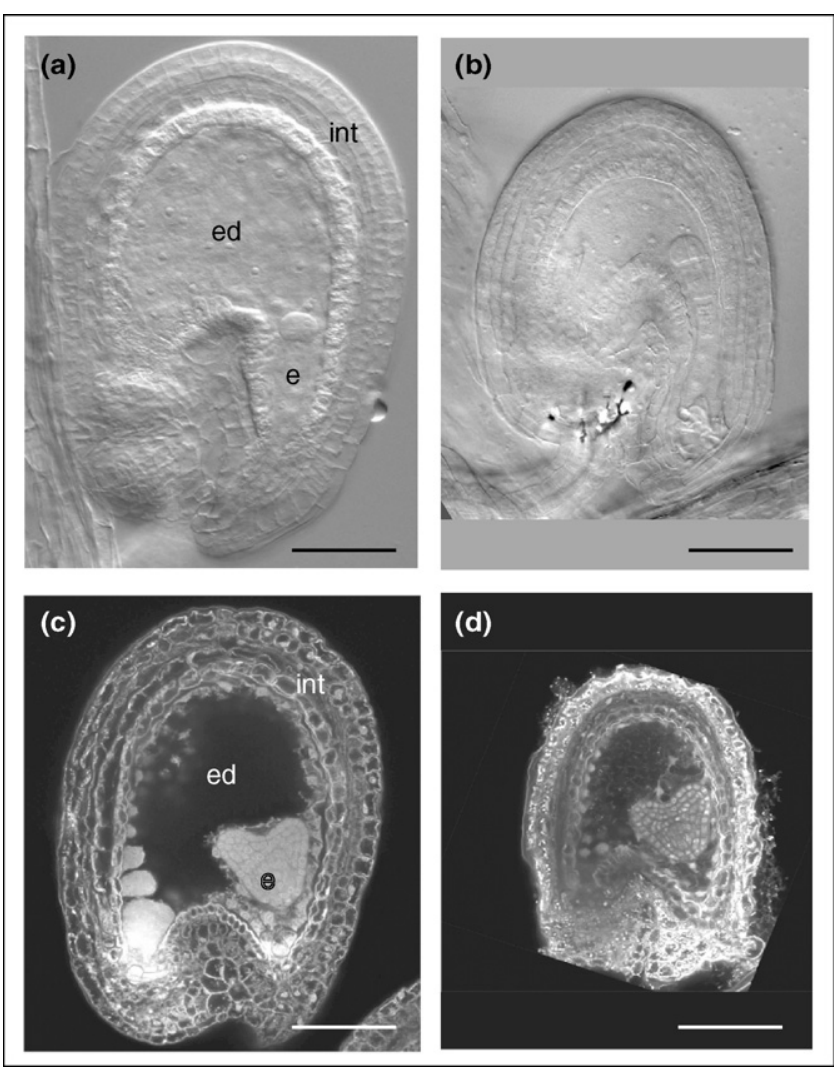

Phenotypes of mutants in which seed development is affected. $(\mathbf{a}, \mathbf{b})$ The effects of pollination of wildtype ovules by cdka;1/+ plants. (a) One and a half days after self-fertilization, the seeds contain an octant stage embryo (e) and stage VI (26-30 nuclei) endosperm (ed) surrounded by seed integuments (int). (b) By contrast, wildtype ovules that are fertilized with cdka; 1 mutant pollen produce seeds that have a two- or four-cellstage embryo one day after pollination. (c,d) In comparison to (c) wildtype seeds, (d) $i k u$ seeds contain an endosperm (ed) that is reduced in size and whose seed integuments (int) do not elongate, whereas embryo growth is not altered.

(Figure 2a). The developing endosperm in $c d k a ; 1$-fertilized seeds arrests after a few rounds of the cell cycle, whereas the embryo develops until the globular stage. Such seeds remain small because they do not expand the seed integument. These observations support the essential role played by endosperm and the comparatively limited role played by the embryo in controlling seed size.

\section{Coordination of maternal and zygotic cues during seed development}

Although extensive screens have been performed, only a handful of mutations that cause maternal effects have been isolated over the past few years [29,30]. However, using a transposon-based mutagenesis approach, a recent study discovered a larger number of such mutants [31], and suggests that there might be a larger diversity of maternal effects than previously thought.
The maternal influence might be inherited by the endosperm by two routes. First, the central cell as progenitor of the endosperm contributes much cytoplasm to the endosperm. The endosperm could inherit maternally derived mRNA and proteins that are located at specific subdomains in the central cell. Indeed, the central cell shows cytological evidence of polarity, which could prefigure the future endosperm antero-posterior organization [32]. Direct maternal effects that originate from the central cell constitute an attractive hypothesis, but one that is supported by little, if any, direct evidence to date. The origin of the maternal effect of DICER-LIKE 1 remains mysterious [33], and the maternal effects that are associated with PROLIFERA (a homolog of MINICHROMOSOME MAINTENANCE 7) are complex and might involve several mechanisms [34].

The second origin of maternal influence on seed development appears to be a specific activation of maternal alleles and silencing of paternal alleles, resulting in maternal genomic imprinting. Two of the components of the FIS complex are subject to maternal genomic imprinting [35,36]. The paternal allele of MEA and FIS2 is silenced. As a consequence, the maternal inheritance of a null allele, mea or fis2, cannot be rescued by a paternal wildtype MEA or FIS2 allele and is sufficient to cause maternal effects on endosperm development $[11,14,15,17]$.

The mechanisms that lead to MEA and FIS2 imprinting are in part distinct ([35,36]; Figure 4). FIS2 is silenced throughout most of the plant life cycle by DNA methylation on a specific region in its promoter [36]. DNA methylation is maintained by the methyltransferase MET1 during vegetative development and male gametogenesis. At the end of female gametogenesis, however, FIS2 silencing is relieved in the central cell by the DNA glycosylase DEMETER (DME). Hence, a transcriptionally active maternal FIS2 allele is provided to the endosperm whereas the paternal FIS2 allele remains silenced by MET1. By contrast, MEA silencing depends on the repressive methylation marks on lysine residue 27 of HISTONE 3 (H3K27) $\left[37^{\bullet \bullet}, 38^{\bullet \bullet}\right]$. H3K27 methylation of the $M E A$ locus depends on the activity of Pc-G complexes that are active during the vegetative phase and male gametogenesis. In endosperm, a loop involving negative feedback by the Pc-G complex, including $M E A$ and FIS2 maintains the silencing of the paternal $M E A$ allele $\left(\left[37^{\bullet \bullet}, 38^{\bullet \bullet}\right]\right.$; Figure 4$)$.

The activation of the maternal allele of $M E A$ in the central cell depends on several mechanisms. Real-time quantitative PCR has shown that $M E A$ expression in the central cell is inhibited by $M E A$ itself [39]. DME is required for $M E A$ activation [40] and is able to remove methylated cytosine from domains linked to the $M E A$ locus $\left[38^{\bullet \bullet}\right]$. However, the degree of DNA methylation of $M E A$ varies depending on natural Arabidopsis accessions 


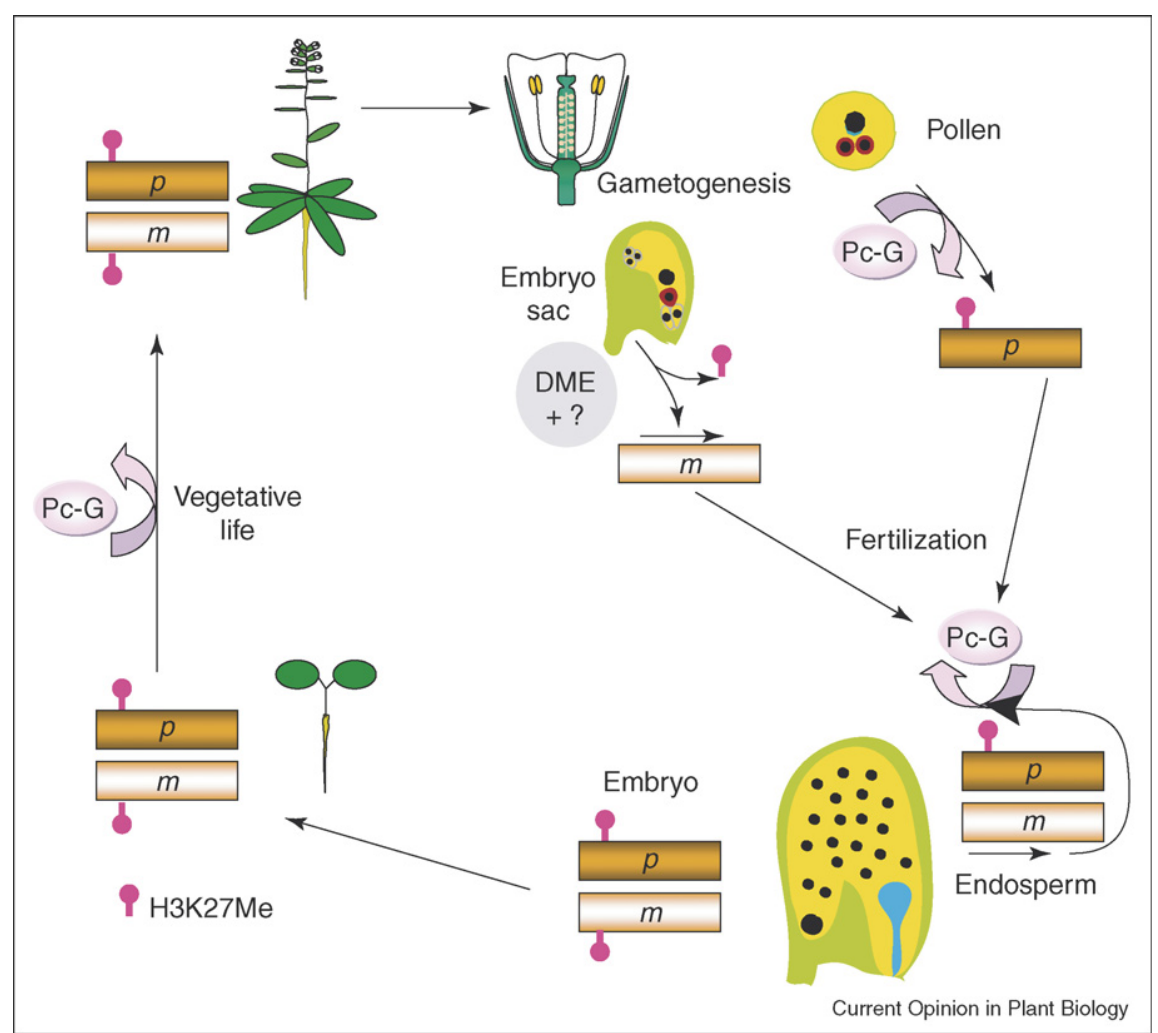

A model for dual control of parental genomic imprinting of MEA in Arabidopsis. The gene MEA is silenced during vegetative development and male gametogenesis by the continuous action of Pc-G complexes that are responsible for maintenance of H3K27 methylation (pink circles) at the MEA locus. MEA expression is activated in the central cell at the end of female gametogenesis by the DNA glycosylase (DME) and potentially by other activities that lead to the removal of H3K27 methylation. After fertilization, the MEA maternal allele $(\mathrm{m})$ is expressed in endosperm and produces the MEA subunit of the PC-G complex, which contains FIS2, FIE and MSI1 and is responsible for maintaining the silencing of the paternal MEA allele $(p)$.

$\left[38^{\bullet \bullet}, 41\right]$. Moreover, DNA methylation does not play a major role in silencing $M E A$ in vegetative tissues or in pollen [ $37^{\bullet \bullet}$ ], and loss of DNA methylation on $M E A$ paternal allele does not alter their silenced state in endosperm $\left[36,38^{\bullet \bullet}\right.$. Hence, DNA methylation probably plays a limited regulatory role in $M E A$ imprinting. What mechanism is responsible for the removal of $\mathrm{H} 3 \mathrm{~K} 27$ methylation that is essential for $M E A$ imprinting is unclear. DME DNA glycosylase activity causes singlestrand breaks in DNA [38*0]. It is possible, therefore, that DNA repair mechanisms that follow DME action involve the deposition of new chromatin and that methylated H3K27 are removed, causing loss of repression of $M E A$ transcriptional activity (Figure 4).

Although accumulating evidence on epigenetic regulation mechanisms has contributed to our understanding of how differential genetic programs are set up in the different components of the seed, little is known about the downstream targets that are controlled by, for example, the Pc-G FIS complex. Small-scale microarray analyses using combinations of fis mutants have to date discovered two genes that are repressed by the FIS-complex, and these genes encode the MADS-box protein PHERES1 (PHE1) and the SKP1-like protein MEIDOS [16]. What functions these proteins have in seed development and growth is not known, but PHE1 has been shown to be expressed exclusively from the paternal genome after fertilization $\left[42^{\bullet}\right]$. In contrast to the gametophytic maternal effects discussed previously, genes such as PHE1 might thus be responsible for activating paternal-specific gene sets in endosperm.

\section{Conclusions}

Our current knowledge on seed development underlines the importance of the endosperm not only as a source of nutrients but also as an integrator of seed growth and development. Different signaling routes are now emerging between the embryo, the endosperm and seed integuments. A reciprocal signaling process between seed integuments and endosperm appears to coordinate the proper course of seed growth. Signals between embryo and endosperm are probably also important for proper seed development but remain to be characterized. 
Significant progress has been made in the understanding of maternal effects and the role of the endosperm as a relay between the mother and the embryo. Here, a possible role of gametophytic maternal factors that are already present in the unfertilized egg and central cell calls for attention.

A major constraint to isolate these signaling components is the small size of reproductive structures in Arabidopsis. This will be overcome in the future, however, by utilizing recent advances in 'genomics' tools, including new sampling techniques, such as laser-assisted micro-dissection, or mRNA-tagging approaches $[43,44]$. The establishment of general as well as spatial and temporal transcriptomes or proteomes is likely to lead to the generation of specific profiles for each reproductive cell type and will be a new source of information $[45,46]$.

\section{Note added in proof}

Three important papers have appeared since we drafted this review $\left[47^{\bullet}-49^{\circ}\right]$.

\section{Acknowledgements}

FB is supported by the Temasek Lifescience laboratory and is affiliated to National University of Singapore. PEG is supported by the Norwegian Research Council. AS is supported by grants from the Volkswagen-Stiftung and the Deutsche Forschungsgemeinschaft. We thank Pauline Jullien and Reza Shirzadi for critical reading of the manuscript and Moritz Nowack for a contribution to Figure 3.

\section{References and recommended reading}

Papers of particular interest, published within the annual period of review, have been highlighted as:

- of special interest

•• of outstanding interest

1. Yadegari R, Drews GN: Female gametophyte development. Plant Cell 2004, 16:S133-S141.

2. Weterings K, Russell SD: Experimental analysis of the fertilization process. Plant Cell 2004, 16:S107-S118.

3. Lord EM, Russell SD: The mechanisms of pollination and fertilization in plants. Annu Rev Cell Dev Biol 2002, 18:81-105.

4. Dresselhaus $\mathrm{T}$ : Cell-cell communication during double fertilization. Curr Opin Plant Biol 2006, 9:41-47.

5. Mori T, Kuroiwa H, Higashiyama T, Kuroiwa T: GENERATIVE

-. CELL SPECIFIC 1 is essential for angiosperm fertilization. Nat Cell Biol 2006, 8:64-71.

This remarkable paper demonstrates the function of a conserved protein that is probably involved in recognition between plant gametes and necessary for their fusion. This protein is also conserved in other unicellular eukaryotes.

6. Durbarry A, Vizir I, Twell D: Male germ line development in Arabidopsis duo pollen mutants reveal gametophytic regulators of generative cell cycle progression. Plant Physiol 2005, 137:297-307.

7. Rotman N, Durbarry A, Wardle A, Yang WC, Chaboud A, Faure JE, Berger F, Twell D: A novel class of MYB factors controls sperm-cell formation in plants. Curr Biol 2005, 15:244-248.

8. Tian HQ: Relationship between double fertilization and the cell cycle in male and female gametes of tobacco. Sex Plant Reprod 2005, 17:243-252.

9. Nowack MK, Grini PE, Jakoby MJ, Lafos M, Koncz C, Schnittger A: -A positive signal from the fertilization of the egg cell sets off endosperm proliferation in angiosperm embryogenesis. Nat Genet 2006, 38:63-67.

The isolation of a mutant in the major cycle regulator CDKA; 1 shows the unexpected activation of central cell division by a signal from the developing embryo. The authors also provide evidence of a selective mechanism of fertilization by a single sperm cell.

10. Iwakawa H, Shinmyo A, Sekine M: Arabidopsis CDKA;1, a cdc2 homologue, controls proliferation of generative cells in male gametogenesis. Plant J 2006, 45:819-831.

11. Grossniklaus U, Vielle-Calzada JP, Hoeppner MA, Gagliano WB: Maternal control of embryogenesis by MEDEA, a polycomb group gene in Arabidopsis. Science 1998, 280:446-450.

12. Luo M, Bilodeau P, Koltunow A, Dennis ES, Peacock WJ, Chaudhury AM: Genes controlling fertilization-independent seed development in Arabidopsis thaliana. Proc Natl Acad Sci USA 1999, 96:296-301.

13. Ohad N, Yadegari R, Margossian L, Hannon M, Michaeli D, Harada JJ, Goldberg RB, Fischer RL: Mutations in FIE, a WD polycomb group gene, allow endosperm development without fertilization. Plant Cell 1999, 11:407-416.

14. Ohad N, Margossian L, Hsu YC, Williams C, Repetti P, Fischer RL: A mutation that allows endosperm development without fertilization. Proc Natl Acad Sci USA 1996, 93:5319-5324.

15. Chaudhury AM, Ming L, Miller C, Craig S, Dennis ES, Peacock WJ: Fertilization-independent seed development in Arabidopsis thaliana. Proc Natl Acad Sci USA 1997, 94:4223-4228.

16. Kohler C, Hennig L, Spillane C, Pien S, Gruissem W, Grossniklaus U: The polycomb-group protein MEDEA regulates seed development by controlling expression of the MADs-box gene PHERES1. Genes Dev 2003, 17:1540-1553.

17. Guitton AE, Page DR, Chambrier P, Lionnet C, Faure JE, Grossniklaus U, Berger F: Identification of new members of FERTILISATION INDEPENDENT SEED polycomb group pathway involved in the control of seed development in Arabidopsis thaliana. Development 2004, 131:2971-2981.

18. Guitton AE, Berger F: Loss of function of MULTICOPY

- SUPPRESSOR OF IRA 1 produces nonviable parthenogenetic embryos in Arabidopsis. Curr Biol 2005, 15:750-754.

This study provides evidence for a single gene activity that is linked to parthenogenetic development in plants, and shows that the controls of cell cycle arrest differ between the two plant female gametes.

19. Ach RA, Taranto $P$, Gruissem W: A conserved family of WD-40 proteins binds to the retinoblastoma protein in both plants and animals. Plant Cell 1997, 9:1595-1606.

20. Ebel C, Mariconti L, Gruissem W: Plant retinoblastoma homologues control nuclear proliferation in the female gametophyte. Nature 2004, 429:776-780.

21. Bracha-Drori K, Shichrur K, Katz A, Oliva M, Angelovici R, Yalovsky S, Ohad N: Detection of protein-protein interactions in plants using bimolecular fluorescence complementation. Plant J 2004, 40:419-427.

22. Wildwater M, Campilho A, Perez-Perez JM, Heidstra R, Blilou I, Korthout H, Chatterjee J, Mariconti L, Gruissem W, Scheres B: The retinoblastoma-related gene regulates stem cell maintenance in Arabidopsis roots. Cell 2005, 123:1337-1349.

23. Garcia D, Saingery V, Chambrier P, Mayer U, Jürgens G, Berger F: Arabidopsis haiku mutants reveal new controls of seed size by endosperm. Plant Physiol 2003, 131:1661-1670.

24. Luo M, Dennis ES, Berger F, Peacock WJ, Chaudhury A: MINISEED3 (MINI3), a WRKY family gene, and HAIKU2 (IKU2), a leucine-rich repeat (LRR) kinase gene, are regulators of seed size in Arabidopsis. Proc Natl Acad Sci USA 2005, 102:17531-17536.

25. Garcia D, Fitz Gerald JN, Berger F: Maternal control of

- integument cell elongation and zygotic control of endosperm growth are coordinated to determine seed size in Arabidopsis. Plant Cell 2005, 17:52-60.

This paper demonstrates that a dialogue between the endosperm and the seed integuments is essential for determination of seed size. 
26. Canales $\mathrm{C}$, Bhatt $\mathrm{AM}$, Scott $\mathrm{R}$, Dickinson $\mathrm{H}$ : EXS, a putative LRR receptor kinase, regulates male germline cell number and tapetal identity and promotes seed development in Arabidopsis. Curr Biol 2002, 12:1718-1727.

27. Schruff MC, Spielman M, Tiwari S, Adams S, Fenby N, Scott RJ: The AUXIN RESPONSE FACTOR 2 gene of Arabidopsis links auxin signalling, cell division, and the size of seeds and other organs. Development 2006, 133:251-261.

28. Haughn G, Chaudhury A: Genetic analysis of seed coat development in Arabidopsis. Trends Plant Sci 2005, 10:472-477.

29. Grini $P E$, Jürgens $G$, Hülskamp $M$ : Embryo and endosperm development is disrupted in the female gametophytic capulet mutants of Arabidopsis. Genetics 2002, 162:1911-1925.

30. Chaudhury AM, Berger F: Maternal control of seed development. Semin Cell Dev Biol 2001, 12:381-386.

31. Pagnussat GC, Yu HJ, Ngo QA, Rajani S, Mayalagu S, Johnson CS, Capron A, Xie LF, Ye D, Sundaresan V: Genetic and molecular identification of genes required for female gametophyte development and function in Arabidopsis. Development 2005, 132:603-614

32. Berger F: Endosperm: the crossroad of seed development. Curr Opin Plant Biol 2003, 6:42-50.

33. Golden TA, Schauer SE, Lang JD, Pien S, Mushegian AR, Grossniklaus U, Meinke DW, Ray A: SHORT INTEGUMENTS1/ SUSPENSOR1/CARPEL FACTORY, a dicer homolog, is a maternal effect gene required for embryo development in Arabidopsis. Plant Physiol 2002, 130:808-822.

34. Springer PS, Holding DR, Groover A, Yordan C, Martienssen RA The essential Mcm7 protein prolifera is localized to the nucleus of dividing cells during the $G_{1}$ phase and is required maternally for early Arabidopsis development. Development 2000, 127:1815-1822.

35. Kinoshita T, Yadegari R, Harada JJ, Goldberg RB, Fischer RL: Imprinting of the MEDEA polycomb gene in the Arabidopsis endosperm. Plant Cell 1999, 11:1945-1952.

36. Jullien PE, Kinoshita T, Ohad N, Berger F: Maintenance of DNA methylation during the Arabidopsis life cycle is essential for parental imprinting. Plant Cell 2006, 18:1360-1372.

37. Jullien PE, Katz A, Oliva M, Ohad N, Berger F: Polycomb group -. complexes self-regulate imprinting of the polycomb group gene MEDEA in Arabidopsis. Curr Biol 2006, 16:486-492.

The authors demonstrate that imprinting of the polycomb group gene MEDEA depends on regulations by Polycomb group complexes. Together with the work described in [36], this study provides evidence for silencing mechanisms during male gametogenesis and endosperm development that are essential for the maintenance of imprinting.

38. Gehring M, Huh JH, Hsieh TF, Penterman J, Choi Y, Harada JJ,

- Goldberg RB, Fischer RL: Demeter DNA glycosylase establishes MEDEA polycomb gene self-imprinting by allelespecific demethylation. Cell 2006, 124:495-506.

This study dissects the biochemical mechanism of DME, which is essential for the activation of the maternal allele of imprinted genes. The authors also provide evidence for the self-regulation of imprinting by the Polycomb group gene MEA in endosperm.
39. Baroux C, Gagliardini V, Page DR, Grossniklaus U: Dynamic regulatory interactions of polycomb group genes: MEDEA autoregulation is required for imprinted gene expression in Arabidopsis. Genes Dev 2006, 20:1081-1086.

40. Choi Y, Gehring M, Johnson L, Hannon M, Harada JJ, Goldberg RB, Jacobsen SE, Fischer RL: DEMETER, a DNA glycosylase domain protein, is required for endosperm gene imprinting and seed viability in Arabidopsis. Cell 2002, 110:33-42.

41. Spillane C, Baroux C, Escobar-Restrepo JM, Page DR, Laoueille S, Grossniklaus U: Transposons and tandem repeats are not involved in the control of genomic imprinting at the MEDEA locus in Arabidopsis. Cold Spring Harb Symp Quant Biol 2004, 69:465-475.

42. Köhler C, Page DR, Gagliardini V, Grossniklaus U: The

- $\quad$ Arabidopsis thaliana MEDEA polycomb group protein controls expression of PHERES1 by parental imprinting. Nat Genet 2005, 37:28-30.

This study provides an elegant demonstration of how the expression of a paternally expressed imprinted gene is controlled in plants.

43. Roy PJ, Stuart JM, Lund J, Kim SK: Chromosomal clustering of muscle-expressed genes in Caenorhabditis elegans. Nature 2002, 418:975-979.

44. Day RC, Grossniklaus U, Macknight RC: Be more specific! Laserassisted microdissection of plant cells. Trends Plant Sci 2005 10:397-406.

45. Honys D, Twell D: Transcriptome analysis of haploid male gametophyte development in Arabidopsis. Genome Biol 2004, 5:R85.

46. Hennig L, Gruissem W, Grossniklaus U, Köhler C: Transcriptional programs of early reproductive stages in Arabidopsis. Plant Physiol 2004, 135:1765-1775.

47. Wang D, Tyson MD, Jackson SS, Yadegari R: Partially

- redundant functions of two SET-domain polycomb-group proteins in controlling initiation of seed development in Arabidopsis. Proc Natl Acad Sci USA 2006, 103:13244-13249.

This study demonstrates redundant functions of the polycomb-group proteins SWINGER and MEDEA in complex with FERTILIZATION-INDEPENDENT SEED 2 in controlling the initiation of endosperm development.

48. Makarevich G, Leroy O, Akinci U, Schubert D, Clarenz O,

- $\quad$ Goodrich J, Grossniklaus U, Köhler C: Different Polycomb group complexes regulate common target genes in Arabidopsis. EMBO reports 2006, 7:947-952.

This careful study reports the location of repressive epigenetic mark on PHERES1 by several Pc-G complexes that act during vegetative and reproductive development.

49. Gutierrez-Marcos JF, Costa LM, Evans MMS: Maternal

- gametophytic baseless1 is required for development of the central cell and early endosperm patterning in maize (Zea mays). Genetics 2006, 174:317-329.

This study provides the exciting report of a direct maternal influence from the female gamete on polarity of zygotic products in plants. 